\title{
Alkaptonuria presenting as lumbar disc prolapse: case report and review of literature
}

\author{
D Raja Reddy ${ }^{1}$ and VSSV Prasad \\ Departments of Neurosurgery, Nizam's Institute of Medical Sciences \& ${ }^{1}$ The Apollo Hospitals, Hyderabad, India
}

\begin{abstract}
Alkaptonuria is a rare genetic disorder caused by deficiency of the enzyme homogentisic acid oxidase, resulting in accumulation of homogentisic acid in various body tissues; it produces a multisystemic disorder with a characteristic bluish-black discolouration of the skin and cartilage, termed ochranosis. Ochranosis primarily involves the large joints of the body including the spine. Spinal involvement produces loss of flexibility and ankylosis of the thoracic and lumbar segments. ${ }^{1}$ The clinical presentation with spondylosis and canal stenosis is common after the third and fourth decades, ${ }^{2}$ but intervertebral disc prolapse is unusual in ochranosis.
\end{abstract}

Keywords: alkaptonuria; ochranosis; disc prolapse; spine

\section{Case report}

A 22 year old male presented with backache and left sided sciatica of 6 weeks duration. Conservative treatment from his general practitioner failed to relieve the pain and he developed paraesthesiae in left lower limb. There was marked restriction of straight leg raising on the left side; weakness of the left ankle dorsiflexors and of the extensor hallucis longus; and decreased sensation over the medical aspect of left foot.

A clinical diagnosis of prolapsed intervertebral disc at L4/L5 on the left side was made, and he was investigated. Plain radiographs of the lumbar spine were unremarkable; magnetic resonance image tomography revealed a prolapse of the L4/5 intervertebral disc (Figure 1). At operation, there was marked hypertrophy of the facet joints with encroachment onto the canal, and there was severe pressure on the L5 left nerve root due to the underlying bulging disc. On incising the annulus the disc material was found to be blackish green in colour and this material changed its colour to pale shades on exposure to the air.

The patient experienced remarkable relief after the operation. The colour of the disc material made us suspect alkaptonuria and examination of the blood, urine and disc material confirmed the diagnosis. Homogentisic acid was $81 \mathrm{mg} / \mathrm{dl}$ in random urine and $110 \mu \mathrm{g} / \mathrm{mg}$ of wet weight disc material. On retrospective analysis of the family history, whilst none of the patient's three brothers had a similar

Correspondence: Dr VSSV Prasad MS, MCh

Division of Neurosurgery, Sunny Brook Health Science Centre, 2075 Bay View Avenue, North York, Ontario, Canada M4N 3MS problem, his father and paternal uncles had undiagnosed spinal problems with the result, developing a stooping posture as they got older. Before discharge the patient was given dietory advice (with low phenylalanine and low tyrosine) in addition to the regular discharge protocol.

\section{Discussion}

Virchow in 1866 coined the term 'ochranosis' to identify the condition characterised by pigmentation of the cartilage, ligaments, tendons and the intima of large blood vessels. ${ }^{3}$ Several decades later, Albrecht and Zdareck in 1902 described its association with alkaptonuria. $^{3}$

The incidence is approximately one in one million of the population, ${ }^{4}$ and approximately one half of all alkaptonuric patients will have evidence of ochranosis. ${ }^{5}$ The first symptoms usually appear in the 3rd or 4th decade. ${ }^{6}$ Sodenberg $(1915)^{7}$ detailed the spinal arthritis associated with ochranosis in 1915 and termed it as 'osteitis deformans alkaptonurica'. The initial presentation usually refers to stiffness of lumbar spine with gradual loss of lordosis and an exaggeration of the thoracic kyphosis. ${ }^{8}$

Radiographic findings demonstrate changes that may not be proportional to the clinical presentation. Gradual disintegration of the disc spaces occurs with marginal osteophytosis of the vertebral bodies. ${ }^{9}$ Multiple vacuum discs ${ }^{10}$ and pseudoblock vertebrae ${ }^{11}$ may be seen. There was no difference in the signal intensities in the discs of our patient in the MRI study, compared to the findings obtained in MRI studies of disc prolapse in 'non-ochranosis patients'. 


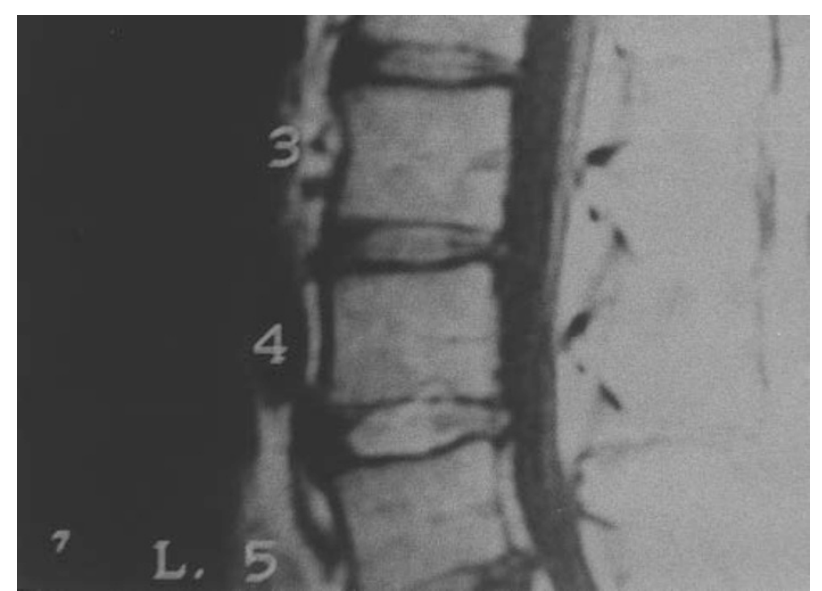

Figure 1 Magnetic resonance tomography showing the prolapsed intervertebral disc at L4 and L5 with significant compression over dural sac

Pathological examination of the spine reveals narrowing of discs with diffuse bluish-black pigmentation. ${ }^{3}$ Lateral disc bulges may be seen and the discs are hard and brittle. ${ }^{12}$ These changes are most dramatic in the lumbar spine. Gradually the discs disappear and leave the vertebral bodies fused. Height loss as great as $15 \mathrm{~cm}$ has been reported. ${ }^{13}$ Sciatica can be an initial presentation and a cauda equina syndrome has also been reported in ochranosis. The disease process most similar to ochranosis is ankylosing spondylitis, but the area of involvement in the former is the intervertebral disc, whereas ligaments, facets and the sacroiliac joints are characteristically involved in the latter. For the same reason disc prolapse is unusual in ochranosis, ${ }^{5}$ although cervical disc ruptures have been reported. ${ }^{14}$

The cardiovascular lesions of ochranosis, include discolouration of the heart valves, endocardium and intima of the aorta. There is an increased incidence of generalised atherosclerosis, and myocardial infarction is the frequent cause of death. Similarly calcification of the heart valves especially calcific aortic stenosis frequently occurs. A change of diet as was prescribed for our patient and prophylactic measures to slow down the progression of this interesting condition increase the survival and quality of life of ochranotic patients.

\section{Acknowledgements}

We are grateful to the National Institute of Nutrition for cooperating with us in formulating a low phenyl alanine, low tyrosine diet for the patient. We thank Dr Sita Devi for providing the biochemical analysis of the disc material.

\section{References}

1 Millea TP, Segal LS, Liss RG, Stayffer ES. Spine fracture in Ochranosis. Report of a case. Clinical Orthorpedics and related Research 1992; 281: $208-211$.

2 Koh KB, Low EH, Ch'Ng SL, Zakiah I. A case of alkaptonuria with root canal stenosis. Singapore medical journal 1994; 35: $106-107$.

3 Oppenheimer BS, Kline BS. Ochranosis with a study of an additional case. Arch Int Med 1992; 29: 732.

4 Gaines JJ. The pathology of alkaptonuric ochranosis. Hum pathol 1989; 20: 40.

5 Eisenberg H. Alkaptonuria, Ochranosis, Arthritis and ruptured intervertebral disk complicated by homologous serum reaction. Arch Int Med 1950; 86: 79.

6 Srsen S. Alkaptonuria. Johns Hopkins Med J 1979; 145: 217.

7 Sodenberg G. Zur Klinik de alkaptonurie, insbesondere uber die Wassermann' sche reaktion und ostitis deformana alcaptonurica. Nordiskmed. Arkiv Afd. 1915; 11.NR.19, 48: 1.

8 Laskar FH, Sargison KD. Ochronotic arthropathy. A review with four case reports. J Bone Joint Surg 1970; 52B: 65.

9 Crissy RE, Day AJ. Ochronosis. A case report. J Bond Joint Surg 1950; 32A: 688.

10 Deeb Z, Frayha RA. Multiple vacuum discs. An early sign of Ochronosis. Radiologic findings in two brothers. $J$ Rheumatology 1976; 3: 82.

11 Justesen P, Andersen PE. Radiologic manifestations of alkaptonuria. Skeletal Radiology 1984; 11: 204.

12 Lichstenstein L, Kaplan L. Hereditory ochronosis. Pathologic changes observed in two necropsied cases. Am J Pathol 1954; 30: 99.

13 Seradge H, Anderson MG. Alkaptonuria and ochronosis. Historic Review and update. Orthop Rev 1978; 7: 41.

14 O'Brien WM, Bert N, La Du, Bunim JT. Biochemical, pathological and clinical aspects of Alkaptonuria, ochranosis and Ochranotic arthropathy. American Journal of Medicine 1963; 34: 813 . 